\title{
APLIKASI TEKNOLOGI UNMANNED AERIAL VEHICLE (UAV) UNTUK MENGIDENTIFIKASI TUTUPAN HUTAN DAN LAHAN DI UNIVERSITAS LANCANG KUNING
}

\section{Forest and Land Cover Identification Using Unmanned Aerial Vehicle (UAV) Technology in Universitas Lancang Kuning}

\author{
Muhammad Ikhwan ${ }^{1}$, Ambar Tri Ratnaningsih ${ }^{1}$, Ika Lestari ${ }^{1}$, Hanifah Ikhsani ${ }^{1}$ \\ ${ }^{1}$ Dosen Fakultas Kehutanan, Universitas Lancang Kuning \\ Jalan Yos Sudarso Km 8 Rumbai Pekanbaru. \\ E-mail:mmighwan@unilak.ac.id,ambar@unilak.ac.id,lestariika@unilak.ac.id,hanifah@unilak.ac.id
}

Diterima: 03 November 2020, Direvisi: 16 Desember 2020, Disetujui: 01 Februari 2021

DOI: 10.31849 /forestra.v16i1.5393

\section{ABSTRACT}

Lancang Kuning University Campus (UNILAK) is one of the campuses that has a fairly wide area and has enormous potential, especially related to the use of space whose potential has not been maximally utilized to support the Tridharma activities. The lack of land use is due to a more detailed inventory of land cover types that have not yet been carried out so that data and information related to existing land cover types are very minimal. It is necessary to identify the type of land cover and land cover characteristics at the Unilak Campus. One of the activities carried out for land cover data collection is land cover inventory activity using applications in the senses and GIS to collect data on land cover types in the study area coverage. Information on the types of land cover can be obtained from land cover data inventory activities through ground check activities or data collection on land cover conditions in the field, using remote sensing technology and a combination of that. The results of the land cover inventory that have been carried out at Unilak are natural forests, plantation forests, developed land, open land, water bodies, shrubs and oil palm plants.

Keywords: Aerial photography, Drone, GIS, Land Cover

\section{ABSTRAK}

Kampus Universitas Lancang Kuning (UNILAK) adalah salah satu kampus yang memiliki kawasan yang cukup luas dan memiliki potensi yang sangat besar, terutama terkait dengan pemanfaatan ruang yang potensinya belum termanfaatkan secara maksimal untuk menunjang kegiatan Tridharma perguruan tinggi. Masih kurangnya pemanfaatan ruang lahan ini disebabkan oleh belum dilakukan inventarisasi jenis penutupan lahan secara lebih detail sehingga data dan informasi terkait jenis penutupan lahan yang ada masih sangat minim, sehingga perlu dilakukan identifikasi jenis penutupan lahan dan karakteristik penutupan lahan di Kampus Unilak. Salah satu kegiatan yang dilakukan untuk pendataan penutupan lahan adalah kegiatan inventarisasi tutupan lahan menggunakan aplikasi dalam inderaja dan GIS untuk melakukan pendataan jenis tutupan lahan dalam cakupan wilayah kajian. Informasi mengenai jenis-jenis tutupan lahan dapat 
diperoleh dari kegiatan inventarisasi data tutupan lahan melalui kegiatan ground check atau pengambilan data kondisi tutupan lahan di lapangan, menggunakan teknologi penginderaan jauh dan kombinasi pengamatan terestis dan pengideraan jauh. HasiI inventarisasi tutupan lahan yang telah dilakukan di Unilak adalah hutan alam, hutan tanaman, lahan terbangun, lahan terbuka, badan air, semak belukar dan tanaman sawit.

Kata kunci: Drone, Foto udara, SIG, Tutupan Lahan.

\section{PENDAHULUAN}

Penutupan lahan didefinisikan sebagai penyebutan kenampakan biofisik di permukaan bumi yang terdiri dari areal vegetasi, lahan terbuka, lahan terbangun, tubuh air dan lahan basah (Lillesand et al. 1990). Salah satu kegiatan yang dilakukan untuk pendataan penutupan lahan adalah kegiatan inventarisasi tutupan lahan. Inventarisasi tutupan lahan merupakan salah satu aplikasi dalam inderaja dan GIS yang digunakan untuk melakukan pendataan jenis tutupan lahan dalam cakupan wilayah kajian. Informasi mengenai jenis-jenis tutupan lahan dapat diperoleh dari kegiatan inventarisasi data tutupan lahan melalui kegiatan ground check atau pengambilan data kondisi tutupan lahan di lapangan, menggunakan teknologi penginderaan jauh dan kombinasi pengamatan terestis dan pengideraan jauh.

Universitas Lancang Kuning, yang disingkat UNILAK berdiri dibawah naungan Yayasan Raja Ali Haji saat ini memiliki lahan dengan luas 57 ha. Penggunaan lahan di dalam kawasan Unilak saat ini berupa gedung rektorat, gedung perpustakaan dan bangunan fakultas. Kampus Universitas Lancang Kuning (UNILAK) adalah salah satu kampus yang memiliki kawasan yang cukup luas dan memiliki potensi yang sangat besar, terutama terkait dengan pemanfaatan ruang yang potensinya belum termanfaatkan secara maksimal untuk menunjang kegiatan Tridharma perguruan tinggi. Masih kurangnya pemanfaatan ruang lahan ini disebabkan oleh belum dilakukan inventarisasi jenis penutupan lahan secara lebih detail sehingga data dan informasi terkait jenis penutupan lahan yang ada masih sangat minim.

Teknologi modern Sistem Informasi Geografi (SIG) dan penginderaan jauh (inderaja) dapat digunakan untuk mendapatkan data spasial digital dengan cepat dan akurat, sehingga mampu menjawab masalah kebutuhan informasi para pemangku kebijakan. Multikonsep dalam inderaja mampu memberikan berbagai informasi spasial dan multi informasi yang lain (multi spektral, multi sensor, multi spasial, multi waktu, multipolarisasi dan multi tahap. Aplikasi teknologi inderaja yang multi konsep 
tersebut dapat dimanfaatkan untuk memprediksi jenis dan karakteristik penutupan lahan yang ada di Unilak.

Pentingnya data dan informasi penginderaan jauh yang rinci, cepat, dan akurat dengan biaya operasional yang murah untuk mengetahui kondisi jenis tutupan lahan di Unilak tentunya menjadi salah satu pendorong berkembangnya teknologi penginderaan jauh. Teknologi penginderaan jauh menggunakan pesawat tanpa awak atau Unmanned Aerial Vehicle (UAV) merupakan salah satu teknologi alternatif yang tidak memerlukan banyak tenaga kerja, memiliki data yang lebih rinci, cepat, dan akurat. Oleh karena itu, untuk mendapatkan informasi dari tutupan lahan di lapangan secara cepat, tidak memerlukan banyak tenaga kerja, akurat, dan relatif murah, maka dilakukanlah penelitian ini yang menggabungkan metode kegiatan pengambilan data di lapangan menggunakan teknologi penginderaan jauh dengan wahana UAV sebagai alat perekaman data UAV banyak digunakan untuk mengidentifikasi jenis dan karakteristik penutupan lahan di Unilak. UAV mudah tersedia, dan dapat menjangkau areal yang luas, dengan perlengkapan sensor relatif kecil, GPS, dan perangkat keras yang terkait lainnya. Sejauh ini UAV telah digunakan untuk mendapatkan citra penginderaan jauh seperti pemantauan kebakaran dan bencana alam, pengamatan satwa liar, dan pengukuran vegetasi dalam kebun anggur, tanaman, dan hutan (Shofiyanti, 2011).

Terkait dengan belum dilakukan inventarisasi penutupan lahan di Unilak dengan menggunakan teknologi UAV, maka perlu dikaji bagaimana kemampuan teknologi UAV untuk mengidentifikasi jenis dan karakteristik penutupan lahan di Unilak. Dalam sebuah perencanaan tata ruang dan penggunaan lahan dikampus Unilak memerlukan data dan informasi pentupan lahan yang cepat, akurat, efektif, efisien dan terbaru, salah satunya adalah metodologi inderaja. Metodologi inderaja yang banyak menggunakan citra satelit optik, yang digunakan saat ini, seringkali terkendala oleh tutupan awan, terutama pada saat musim hujan. Disamping itu ketergantungan pada data satelit memerlukan biaya yang besar serta lambatnya pengadaan data sehingga menyebabkan informasi terlambat diperoleh. Pemotretan udara dengan menggunakan pesawat tanpa awak (UAV) merupakan salah satu teknologi alternatif untuk mendapatkan data jenis dan karakteristik penutupan lahan di kawasan kampus Unilak akan lebih detil, real time, cepat dan lebih murah. Adapun tujuan dari penelitian ini adalah mengidentifikasi jenis penutupan lahan di Kampus Unilak dan 
karakteristik penutupan lahan di Kampus Unilak.

\section{METODE PENELITIAN}

Penelitian ini dilaksanakan di kawasan Universitas Lancang Kuning Penelitian ini dilaksanakan pada bulan November 2019 Maret 2020. Alat yang digunakan pada penelitian ini yaitu Global Positioning System (GPS), kamera digital, smartphone yang dilengkapi dengan aplikasi Dji Go 4 dan Pix4dCapture, UAV jenis Dji Phantom 4, tally sheet, dan alat tulis. Proses pengolahan data dilakukan dengan bantuan komputer yang memiliki software ArcGIS version 10.3, Quantum GIS version 2.14.6, Agisoft Photoscan, Microsoft Word, dan Microsoft Excel.

Data yang akan digunakan dalam penelitian ini berupa data primer dan data sekunder. Data primer yang digunakan yaitu data yang diperoleh langsung dari hasil pengamatan lapang berupa ground check di beberapa lokasi penelitian dan data foto udara yang diambil langsung di lapangan menggunakan wahana UAV. Data sekunder yang digunakan yaitu data shapefile peta batas administrasi kawasan Universitas Lancang Kuning, peta jaringan jalan dan sungai.

\section{Metode Pengumpulan Data}

\section{a. Persiapan}

Persiapan dilakukan dengan mempelajari pustaka terkait penelitian yang akan dilaksanakan serta mempersiapkan alat dan data sekunder yang dibutuhkan dalam penelitian. Sebelum dilakukannya penelitian langsung di lokasi penelitian, dilakukan latihan pembuatan perencanaan jalur terbang UAV dan latihan penerbangan UAV jenis $D j i$ Phantom 4 di Universitas Lancang Kuning.

Penentuan jalur terbang UAV yaitu berupa penentuan lokasi atau batas kawasan Universitas Lancang Kuning yang akan dipotret menggunakan UAV. Hal ini sangat penting untuk efektivitas waktu pengambilan data lapang yang dibutuhkan. Adapun penentuan lokasi atau batas yang akan menjadi jalur terbang UAV didasarkan pada keberagaman kelas tutupan lahan yang didapat dari data sekunder.

\section{b. Menentukan titik pengamatan lapangan dengan bantuan citra resolusi tinggi}

Penentuan titik lapang didasarkan pada keterwakilan kelas hutan dan kondisi tutupan lahannya serta didukung oleh data shapefile maupun data dan informasi tutupan lahan dari citra resolusi tinggi. Kelas penutupan hutan dan lahan yang terpilih 
kemudian diamati pada citra resolusi tinggi Google Earth tahun 2018 dalam software Quantum GIS version untuk melihat kondisi lokasi pengambilan data lapang yang kemudian menjadi dasar untuk pengambilan titik pengamatan lapang. Setiap 1 kelas penutupan lahan yang ada di Unilak kemudian diambil sampel minimal 1 titik pengamatan lapang dan 1 titik blok terbang UAV yang dapat mewakili adanya perbedaan tutupan lahan.

\section{c. Pengambilan Data di Lapangan}

1. Pengamatan Lapang

Pengamatan lapang dilakukan dengan mendatangi titik pengamatan yang telah direncanakan untuk mengetahui kondisi lapang yang sebenarnya dengan bantuan GPS untuk mengetahui koordinat titik sesuai perencanaan agar tidak terjadi penyimpangan. Pengamatan kondisi tutupan lahan di lapangan dilakukan secara deskriptif dan mencatat hasil pengamatan ke dalam tally sheet yang mencakup koordinat titik pengamatan, jenis tanaman, kerapatan, dan kondisi tapak. Selain itu dilakukan juga pengambilan gambar di lapangan menggunakan kamera digital.

\section{Pengambilan Foto Udara}

Pengambilan foto udara dilakukan dengan menerbangkan wahana UAV jenis $D j i$ Phantom 4 berdasarkan rencana jalur terbang yang sudah dibuat. Tinggi terbang pesawat UAV adalah 135 meter. UAV diterbangkan secara autopilot menggunakan sistem GPS yang terpasang pada UAV sebagai sistem navigasi, dan dikontrol menggunakan remote controller yang sudah disambungkan dengan smartphone yang memiliki aplikasi Pix4dCapture untuk mengamati secara langsung data foto udara yang direkam dan posisi UAV pada saat itu.

\section{d. Pengolahan Data}

\section{Proses orthomosaic}

Orthophoto merupakan foto udara yang telah dikoreksi geometris dan menggambarkan objek dalam kondisi yang sebenarnya. Orthomosaic merupakan proses mosaik orthophoto yang dibuat dari kumpulan hasil foto udara yang memiliki titik koordinat geometris (Radiansyah, 2017). Berikut proses orthomosaic menggunakan software Agisoft Photoscan untuk menghasilkan orthophoto:

a) Import photo dan rekonstruksi jalur terbang

Tahap ini merupakan tahapan paling awal untuk input hasil foto udara yang akan dijadikan orthophoto. Pada tahap ini hasil foto udara yang telah diinput kemudian diseleksi dengan pendekatan posisi dan ketinggian foto udara.

b) Align Photo 
Align photos dilakukan untuk mengidentifikasi titik-titik yang ada di masing-masing foto dan melakukan proses matching titik yang sama di dua atau lebih foto udara.

\section{c) Build dense point clouds}

Dense point clouds adalah kumpulan titik tinggi dalam jumlah ribuan hingga jutaan titik yang dihasilkan dari pemrosesan fotogrametri foto udara. Tahap ini merupakan tahap yang menghasilkan model tiga dimensi yang lebih detail dalam penggambaran objek sebenarnya.

\section{d) Build mesh}

Tahap pembentukan poligon pada permukaan objek yang terbentuk berdasarkan dense point clouds. Poligon tersebut akan membentuk segitiga yang saling terhubung sehingga terbentuk permukaan objek.

\section{e) Build texture}

Tahap ini merupakan pembentukan tekstur atau model fisik tiga dimensi dari objek yang ada di area perekaman foto.

\section{f) Export orthophoto}

Orthophoto merupakan hasil export dari model tiga dimensi yang sudah memiliki tekstur dan memperlihatkan kondisi lapang yang sebenarnya dan memiliki format (.tiff).

g) Interpretasi citra secara visual

Menurut Purwadhi (2001), interpretasi visual merupakan perbuatan mengkaji citra dengan maksud mengidentifikasi objek yang tergambar di dalam citra. Interpretasi visual citra didasarkan pada pengenalan ciri objek secara keruangan (spasial). Interpretasi citra secara visual dilakukan dengan membuat deliniasi batas antar kelas hutan dengan cara digitasi langsung di layar komputer (on screen digitation) dengan software ArcGis 10.3 dan didukung dengan hasil klasifikasi tutupan lahan berdasarkan pengamatan lapang. Dalam interpretasi citra secara visual, elemen-elemen dasar untuk melakukan penafsiran atau disebut juga kunci interpretasi mencakup: rona dan warna, bentuk, ukuran, pola, tekstur, bayangan, lokasi, dan asosiasi (Jaya 2015).

Unsur interpretasi yang dimaksud disini adalah:

1) Rona / warna

Rona dan warna merupakan unsur pengenal utama atau primer terhadap suatu obyek pada citra penginderaan jauh. Fungsi utama adalah untuk identifikasi batas obyek pada citra. Penafsiran citra secara visual menuntut tingkatan rona bagian tepi yang jelas, hal ini dapat dibantu dengan teknik penajaman citra (enhacement). Rona merupakan tingkat/gradasi keabuan yang teramati pada citra penginderaan jauh yang dipresentasikan secara hitam-putih. Permukaan obyek yang basah akan cenderung 
menyerap cahaya elektromagnetik sehingga akan nampak lebih hitam disbanding obyek yang relative lebih kering.

Warna merupakan ujud yang yang tampak mata dengan menggunakan spectrum sempit, lebih sempit dari spectrum elektromagnetik tampak (Sutanto, 1986). Contoh obyek yang menyerap sinar biru dan memantulkan sinar hijau dan merah maka obyek tersebut akan tampak kuning. Dibandingkan dengan rona , perbedaaan warna lebih mudah dikenali oleh penafsir dalam mengenali obyek secara visual. Hal inilah yang dijadikan dasar untuk menciptakan citra multispektral.

2) Bentuk Bentuk dan ukuran merupakan asosiasi sangat erat.

Bentuk menunjukkan konfigurasi umum suatu obyek sebagaimana terekam pada citra penginderaan jauh. Bentuk mempunyai dua makna yakni : bentuk luar / umum dan bentuk rinci atau sususnana bentuk yang lebih rinci dan spesifik.

\section{3) Ukuran}

Ukuran merupakan bagian informasi konstektual selain bentuk dan letak. Ukuran merupakan atribut obyek yang berupa jarak , luas , tinggi, lereng dan volume (Sutanto, 1986). Ukuran merupakan cerminan penyajian penyajian luas daerah yang ditempati oleh kelompok individu.

\section{4) Tekstur}

Tekstur merupakan frekuensi perubahan rona dalam citra (Kiefer, 1979). Tekstur dihasilkan oleh kelompok unit kenampkan yang kecil, tekstur sering dinyatakan kasar,halus, ataupu belang-belang (Sutanto, 1986). Contoh hutan primer bertekstur kasar, hutan tanaman bertekstur sedang, tanaman padi bertekstur halus.

\section{5) Pola}

Pola merupakan karakteristik makro yang digunakan untuk mendiskripsikan tata ruang pada kenampakan di citra. Pola atau susunan keruangan merupakan ciri yang yang menandai bagi banyak obyek bentukan manusia dan beberapa obyek alamiah. Hal ini membuat pola unsure penting untuk membedakan pola alami dan hasil budidaya manusia. Sebagai contoh perkebunan karet , kelapa sawit sanagt mudah dibedakan dari hutan dengan polanya dan jarak tanam yang seragam.

\section{6) Bayangan}

Bayangan merupakan unsure sekunder yang sering embantu untuk identifikasi obyek secara visual, misalnya untuk mengidentifikasi hutan jarang, gugur daun, tajuk (hal ini lebih 
berguna pada citra resolusi tinggi ataupun foto udara)

\section{7) Situs}

Situs merupakan konotasi suatu obyek terhadap factor-faktor lingkungan yang mempengaruhi pertumbuhan atau keberadaan suatu obyek. Situs bukan cirri suatu obyek secara langsung, teapi kaitanya dengan factor lingkungan. Contoh hutan mangrove selalu bersitus pada pantai tropic, ataupun muara sungai yang berhubungan langsung dengan laut (estuaria).

\section{8) Asosiasi (korelasi )}

Asosiasi menunjukkan komposisi sifat fisiognomi seragam dan tumbuh pada kondisi habitat yang sama. Asosiasi juga berarti kedekatan erat suatu obyek dengan obyek lainnya. Contoh permukiman kita identik dengan adanya jaringan tarnsportasi jalan yang lebih kompleks dibanding permukiman pedesaan. Konvergensi bukti Dalam proses penafsiran citra penginderaan jauh sebaiknya digunakan unsure diagnostic citra sebanyak mungkin. Hal ini perlu dilakukan karena semakin banyak unsure diagnostic citra yang digunakan semakin menciut lingkupnya untuk sampai pada suatu kesimpulan suatu obyek tertentu. Konsep ini yang sering disebut konvergensi bukti.

\section{HASIL DAN PEMBAHASAN}

Hasil Orthophoto foto udara dengan menggunakan pesawat tanpa awak (Unmanned Aerial Vehicle/UAV) untuk kawasan Universitas Lancang Kuning, dapat dilihat pada Gambar 1. Foto udara yang dihasilkan dari proses orthomosaic tidak semua dapat diproses Foto udara yang dihasilkan dari proses menjadi orthophoto, karena tidak semua foto udara memiliki keterkaitan yang baik secara spasial maupun geometris. Hal tersebut dapat dilihat dari adanya ruang kosong, blur, atapun orthophoto yang berwarna kehitaman. Faktor yang mempengaruhi pengambilan gambar menggunakan wahana UAV diantaranya yaitu kecepatan terbang, tinggi terbang, cuaca di sekitar areal penerbangan, topografi di areal penerbangan, dan overlap.

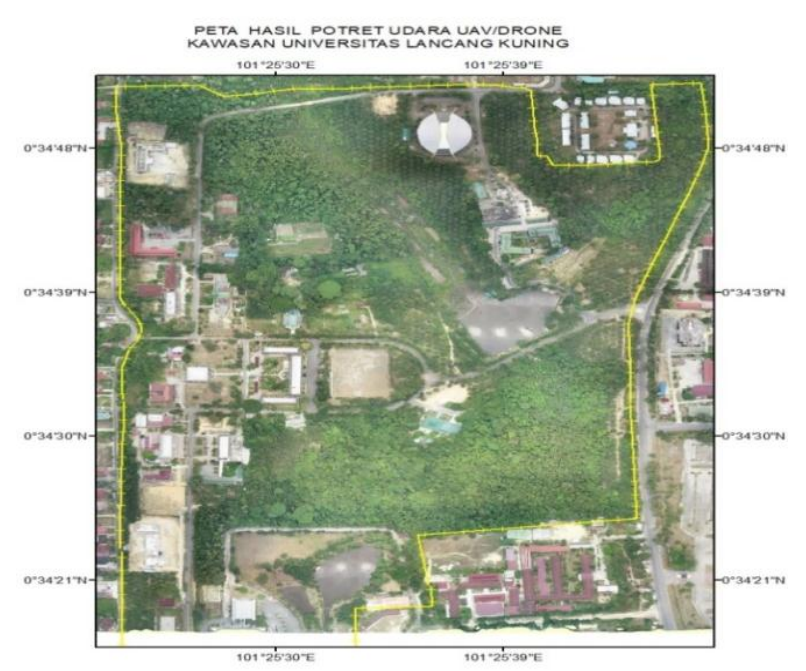

Gambar 1. Peta potret udara UAV di kawasan Universitas Lancang Kuning 
Kecepatan terbang rata-rata yang digunakan ketika pengambilan data lapang yaitu $10 \mathrm{~m} / \mathrm{s}$. Penelitian ini tidak melakukan perbandingan kecepatan terbang yang berbeda-beda. Kecepatan terbang sangat berpengaruh terhadap penentuan shutter speed untuk menghindari nilai Apparent Image Motion (AIM) yang besar. Nilai AIM yang besar dapat menyebabkan objek dalam foto menjadi kabur (blur) dan hasil orthophoto pun menjadi sulit diinterpretasi karena terjadi pergerakan, sehingga pengenalan objek fotonya menjadi lebih sulit (Rosaji et al. 2015). Untuk menghindari nilai AIM yang besar, maka dibutuhkan pengaturan kecepatan terbang UAV. Kecepatan terbang yang baik pada UAV jenis Dji Phantom 4 yaitu berkisar $10 \mathrm{~m} / \mathrm{s}$ hingga $15 \mathrm{~m} / \mathrm{s}$.

Faktor kedua yang berpengaruh dalam pengambilan foto udara yaitu tinggi terbang UAV. Pengaturan tinggi terbang dilakukan untuk mendapatkan hasil foto dengan kualitas yang baik. Ketinggian terbang yang digunakan yaitu $135 \mathrm{~m}$ sehingga menghasilkan skala foto udara sebesar 1:5.000 dari permukaan tanah relatif tetap. Ketinggian terbang $100 \mathrm{~m}$ dapat mencakup area seluas 2030 ha sedangkan ketinggian terbang $150 \mathrm{~m}$, area yang dapat dicakup berkisar 40-50 ha. Dapat disimpulkan bahwa semakin tinggi terbang UAV, area yang tercakup semakin luas, namun jarak sensor perekam (kamera) dengan objek juga akan semakin jauh sehingga resolusi spasialnya akan semakin rendah. Ketinggian terbang UAV yang baik bergantung pada tujuan pengambilan datanya, apabila kebutuhan pengambilan data bertujuan untuk mendapatkan areal yang seluas-luasnya maka UAV dapat diterbangkan pada ketinggian lebih dari 150 meter dengan perizinan penerbangan berdasarkan Peraturan Menteri Perhubungan PM No 90 Tahun 2015. Namun apabila tujuan pengambilan data UAV yaitu untuk mendapatkan kualitas foto udara sebaik mungkin atau dengan resolusi spasial yang tinggi, mak a UAV dapat diterbangkan pada ketinggian kurang dari 150 meter

Faktor ketiga yang berpengaruh dalam pengambilan foto udara yaitu cuaca di areal penerbangan. UAV pada dasarnya merupakan wahana perekaman data penginderaan jauh yang dapat terbang di bawah awan, namun pada kondisi areal dengan ketinggian tertentu yang biasanya tertutup kabut akan mempengaruhi perekaman data UAV. Apabila UAV terbang di antara kabut maka hasil foto tutupan lahannya akan tertutup kabut sehingga tutupan lahannya tidak terlihat dengan jelas. Selain itu, perbedaan waktu perekaman data juga akan mengakibatkan adanya kontras antar hasil foto. Perbedaan warna dan rona hasil foto udara tentunya akan menjadi suatu 
permasalahan dalam proses interpretasi visual seperti sulitnya interpreter untuk menginterpretasi jenis tanaman yang sama namun dengan warna yang berbeda akibat adanya kontras. Waktu pengambilan foto udara yang baik menggunakan wahana UAV yaitu pada saat cuaca cerah, karena pada saat cuaca cerah, foto udara yang dihasilkan akan memiliki kualitas yang baik tanpa adanya kontras maupun tutupan kabut yang menghalangi

Faktor keempat yang berpengaruh dalam pengambilan foto udara yaitu topografi di areal penerbangan. Banyaknya topografi curam di areal penerbangan, tentunya menjadi salah satu faktor paling berpengaruh dalam pengambilan foto udara di lapang. Topografi yang curam menyebabkan sulitnya akses untuk mencapai lokasi penerbangan yang diinginkan. Lokasi penerbangan pada topografi curam mengharuskan titik penerbangan pesawat harus berada pada titik tertinggi di wilayah tersebut. Hal tersebut dilakukan untuk mengurangi resiko banyaknya rintangan yang dihadapi oleh UAV. Perbedaan topografi di areal penerbangan menyebabkan terjadinya terrain distortion pada hasil orthophoto.

Pada topografi yang curam, untuk mengatasi terrain distortion dapat dilakukan penerbangan dengan menaikkan overlap, menurunkan kecepatan terbang, dan menaikkan tinggi terbang agar luas areal yang dapat dicakup untuk pengambilan data lebih luas dan foto udara yang didapatkan akan lebih banyak. Karena semakin banyak foto udara yang dihasilkan maka akan semakin banyak foto udara yang dapat digabungkan dan hasilnya akan semakin baik (Radiansyah, 2017). Namun terrain distortion tidak dapat diatasi pada foto udara yang berada di tepi blok terbang karena tidak memiliki overlap di seluruh foto sehingga foto yang dihasilkan tidak dapat dikoreksi dengan baik

Faktor kelima yang berpengaruh dalam pengambilan foto udara yaitu overlap. Overlap merupakan tumpang tindih foto, meliputi areal yang sama dalam satu jalur terbang, sedangkan sidelap adalah tumpang tindih antara foto-foto yang berdekatan dalam jalur penerbangan pararel (Philipson, 2012). Foto udara yang memiliki overlap, pada saat dilakukan orthomosaic menjadi orthophoto tentunya akan mengalami koreksi seperti hasil orthophoto yang berada di tengah areal efektif, berbeda dengan foto udara yang tidak memiliki overlap maka hasil orthophotonya tidak terkoreksi sehingga menyebabkan terjadinya displacement.

Dalam pengambilan data lapang, overlap yang terdiri dari side lap dan front lap yang digunakan yaitu sebesar $70 \%$. Besarnya 
overlap yang digunakan pada pengambilan data diperlukan untuk menghindari gap atau ruang kosong pada hasil orthophoto. Overlap yang besar dalam pengambilan data menggunakan wahana UAV dibutuhkan karena UAV memiliki ukuran yang kecil dan massa yang ringan sehingga stabilitas UAV sangat dipengaruhi oleh iklim mikro seperti angin. Angin yang bertiup kencang menyebabkan terjadinya kesulitan dalam mempertahankan UAV untuk dapat terbang sesuai rencana jalur penerbangan. Apabila kecepatan anginnya besar, dapat menyebabkan UAV menjauhi jalur terbang sehingga mengakibatkan adanya gap pada hasil orthophoto. Berbeda dengan potret udara konvensional yang menggunakan pesawat konvensional. Pesawat konvensional cenderung memiliki ukuran yang besar dan massa yang berat sehingga pengaruh iklim mikro terhadap hasil foto udara sangatlah kecil. Overlap yang digunakan pada pesawat konvensional biasanya berkisar 30\% sehingga luas cakupan foto udara yang dihasilkan akan lebih besar dibandingkan menggunakan wahana UAV dan kemungkinan untuk adanya gap menjadi lebih kecil.

Faktor-faktor pengaruh dalam perekaman foto udara menggunakan wahana UAV dapat diatasi dengan beberapa teknik. Perekaman foto udara dengan wahana UAV sebaiknya dilakukan dengan overlap lebih dari $60 \%$ atau menggunakan nilai overlap yang besar untuk menghindari gap maupun displacement, mengatur tinggi terbang berkisar 100-150 meter untuk mendapatkan resolusi spasial yang baik, dan menggunakan kecepatan terbang 10-15 m/s untuk menghindari nilai AIM yang besar.

Pengaturan tersebut dapat dilakukan pada aplikasi DroneDeploy yang ada pada smartphone yang tersambung dengan remote controller. Selain beberapa pengaturan tersebut, perekaman data juga perlu memperhatikan kondisi berupa topografi yang ada di areal penerbangan untuk menghindari banyaknya rintangan berupa pohon yang dihadapi oleh UAV baik dari arah depan maupun arah samping UAV dengan cara menentukan titik perekaman data pada titik tertinggi di lokasi penelitian. Waktu perekaman data dengan wahana UAV pada saat cuaca cerah merupakan waktu perekaman paling baik karena akan menghasilkan kualitas foto yang baik dengan rona terang dan tidak tertutup oleh kabut sehingga mempermudah identifikasi objek yang terekam

Pengenalan obyek merupakan bagian vital dalam interpretasi foto udara UAV. Untuk itu identitas dan jenis obyek pada foto sangat diperlukan dalam analisis memecahkan masalah yang dihadapi. Karakteristik obyek 
pada foto dapat digunakan untuk mengenali obyek yang dimaksud dengan unsur interpretasi. Sembilan (9) unsur interpretasi yang dimaksud disini adalah : rona/warna, bentuk, ukuran, tekstur, pola, bayangan, situs, asosiasi, dan konvergensi bukti. Hasil interpretasi berdasarkan 9 unsur penafsiran pada poto udara UAV diperoleh jenis penutupan lahan di kawasan Universitas Lancang Kuning terdiri dari : Hutan alam, hutan tanaman sejenis, badan/tubuh air, lahan terbuka, lahan terbangun, dan semak belukar. Pembahasan jenis tutupan dan karakteristik dari masing-masing tutupan lahan adalah sebagai berikut

\section{a. Hutan Alam}

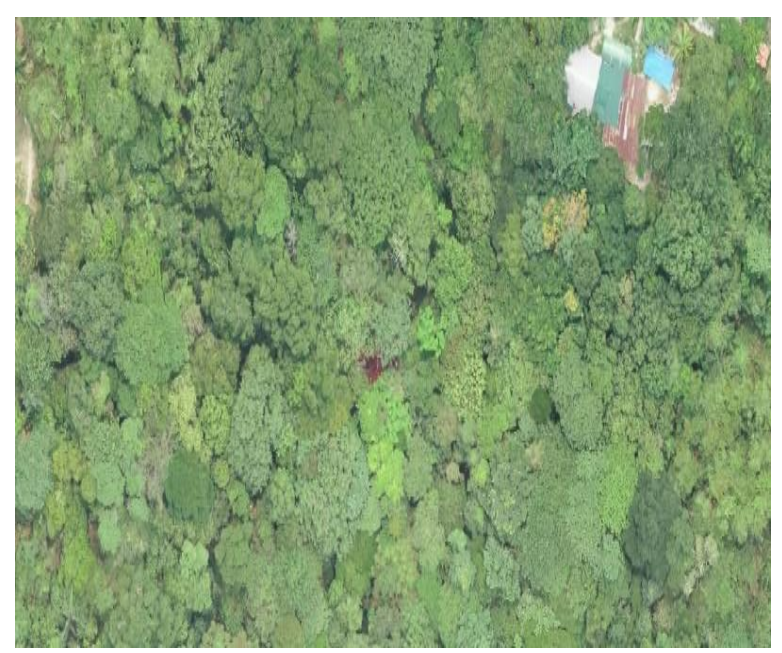

Gambar 2. Orthophoto Tutupan Hutan Alam (Arboretum)

Kenampakkan objek hutan alam pada orthophoto yang ditunjukkan oleh Gambar 2 yang dicirikan dengan rona agak gelap dan warna hijau tua dengan tekstur kasar dan pola mengelompok, serta bentuk tajuk membulat.

\section{b. Tegakan Jenis}

Kenampakkan objek tegakan sejenis pada orthophoto yang ditunjukkan oleh Gambar 3 yang dicirikan dengan rona agak terang dan warna hijau muda dengan tekstur halus dan pola mengelompok, serta bentuk tajuk membulat.

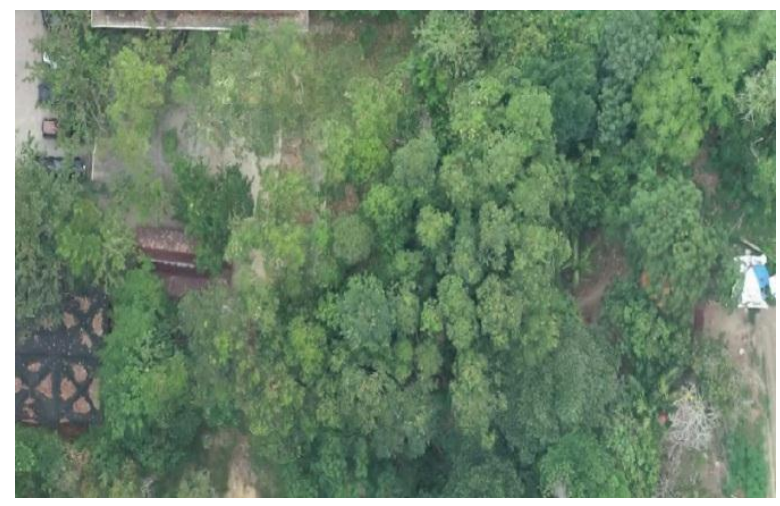

Gambar 3. Orthophoto Tegakan Sejenis

\section{c. Lahan Terbangun}

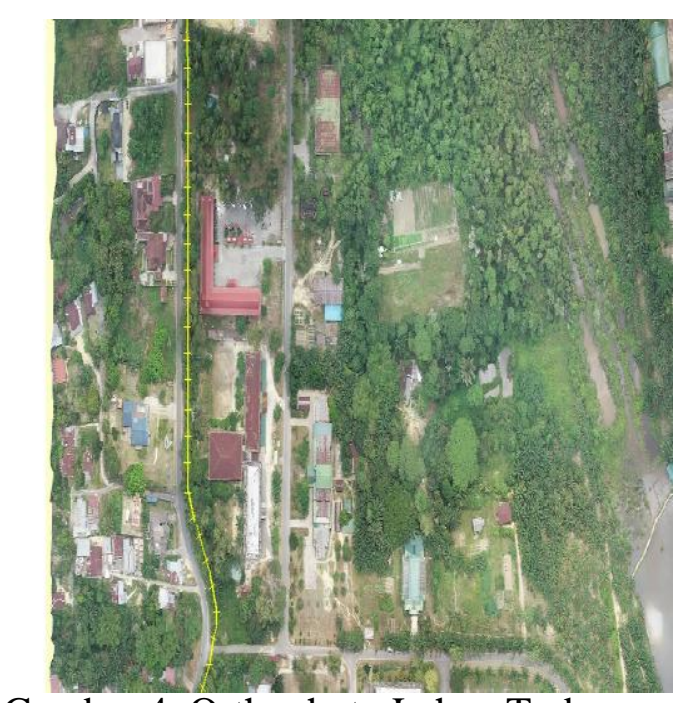

Gambar 4. Orthophoto Lahan Terbangun Untuk Sampel Ke Satu 
Sampel pertama lahan terbangun di kawasan Unilak adalah bangunan gedung Fakultas Pertanian, Fakultas Tekhnik, FKIP dan Fakultas Kehutanan. Kenampakkan objek lahan terbangun pada orthophoto yang ditunjukkan oleh Gambar 4 yang dicirikan dengan rona cerah dan warna merah hingga merah hati, dengan tekstur halus dan pola teratur serta bentuk bangunan tampak dari atas seperti huruf "L" (gedung FKIP), persegi empat (gedung fahutan), dan persegi panjang (gedung faperta). Sample kedua lahan terbangun adalah gedung rektorat, gedung pustaka dan gedung pascasarjana pada Gambar 5 dibawah ini.

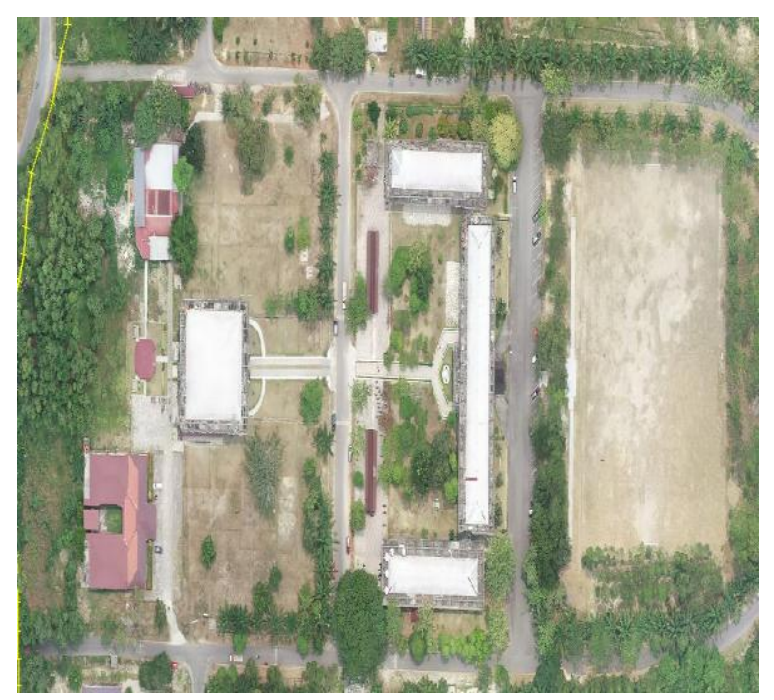

Gambar 5. Orthophoto Lahan Terbangun Untuk Sampel Ke Dua

Kenampakkan objek lahan terbangun pada pada orthophoto yang ditunjukkan oleh Gambar 4 yang dicirikan dengan rona cerah/terang dan warna merah hati dan putih dengan tekstur halus dan pola teratur, serta bentuk bangunan dari atas seperti huruf "U" (Gedung Rektorat dan Pascasarjana). Sampel ketiga lahan terbangun di kawasan Unilak adalah bangunan Fakultas Hukum Kenampakkan objek atap gedung pada orthophoto yang ditunjukkan oleh Gambar 6 yang dicirikan dengan rona cerah/terang dan warna hijau sangat muda, dengan tekstur halus dan pola teratur serta bentuk huruf " $U$ " dan persegi empat.

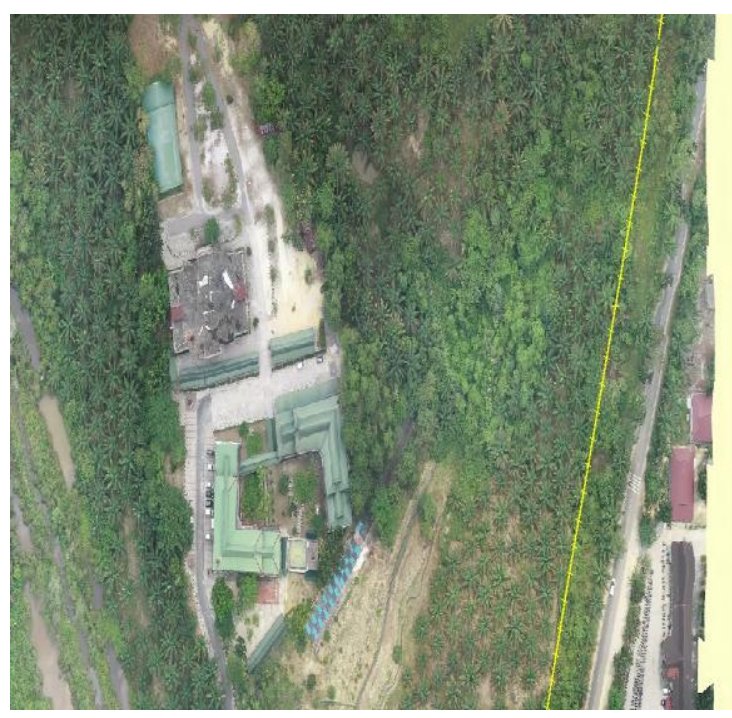

Gambar 6. Orthophoto Lahan Terbangun Pada Sampel Ketiga

\section{d. Badan Air}

Kenampakkan objek badan air pada pada orthophoto yang ditunjukkan oleh Gambar 7 yang dicirikan dengan rona terang 
dan warna abu-abu dengan tekstur halus dan bentuk lahan seperti bangun datar.

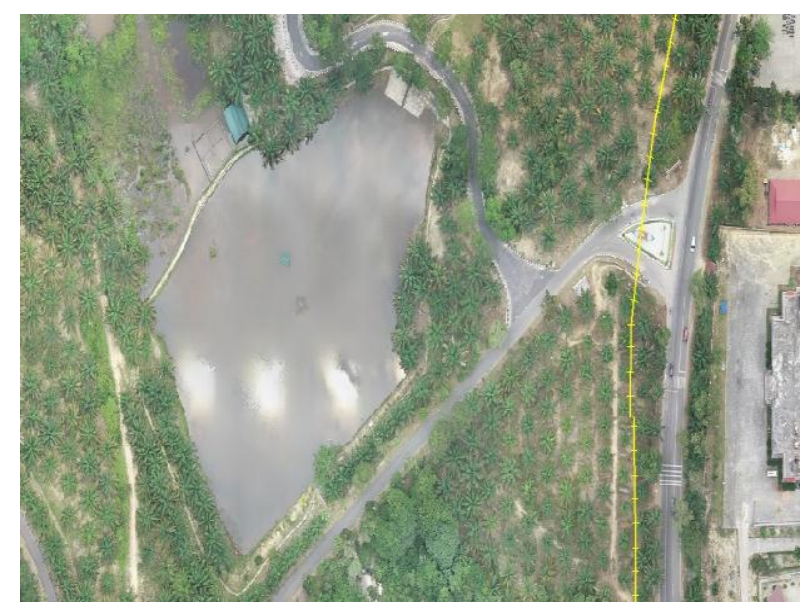

Gambar 7. Orthophoto Badan Air

\section{e. Semak Belukar}

Kenampakkan objek semak belukar pada pada orthophoto yang ditunjukkan oleh Gambar 8 dicirikan dengan rona agak cerah dan warna hijau hingga hijau muda dengan tekstur agak kasar dan pola mengelompok serta bentuk tajuk vegetasi membulat.

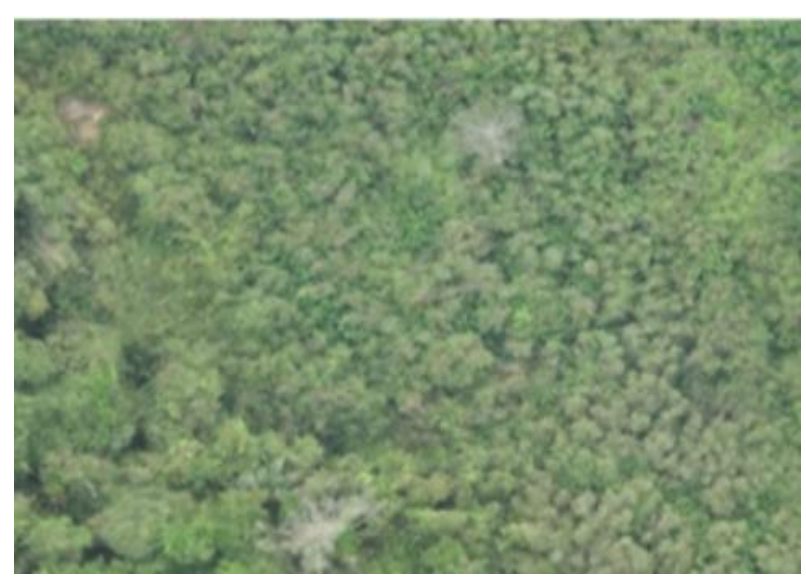

Gambar 8. Orthophoto Semak Belukar

\section{f. Lahan Terbuka}

Kenampakkan objek lahan terbuka pada orthophoto yang ditunjukkan oleh Gambar 9 dicirikan dengan rona cerah dan warna abuabu hingga coklat muda dengan tekstur halus dan pola teratur serta bentuk persegi empat dan persegi panjang.

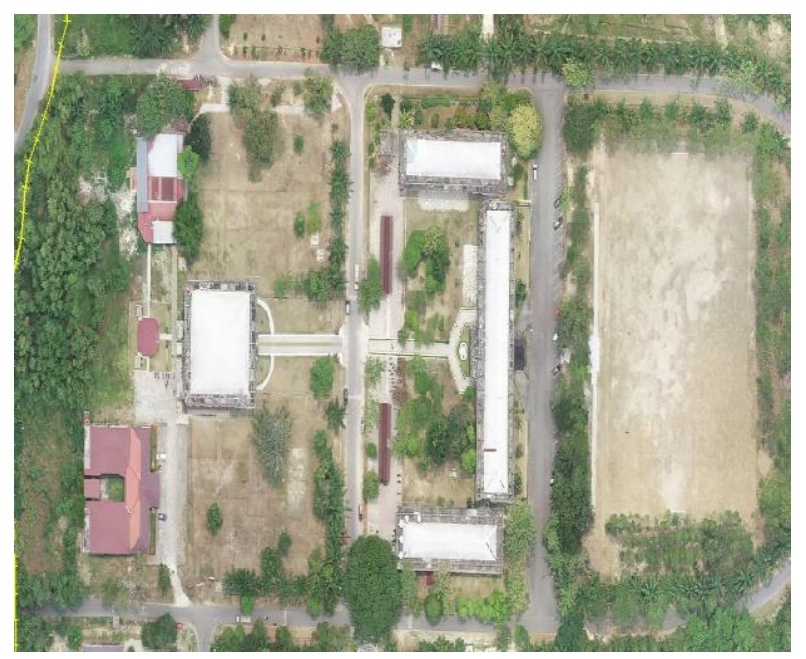

Gambar 9. Orthophoto Lahan Terbuka

\section{KESIMPULAN DAN SARAN}

\section{A. Kesimpulan}

Kesimpulan dari penelitian ini adalah :

1. Kelas tutupan lahan yang dapat diidentifikasi dari foto udara UAV untuk kawasan Universitas Lancang Kuning adalah : hutan alam, hutan tanaman, lahan terbangun, lahan terbuka, badan air, semak belukar dan tanaman sawit.

2. Orthophoto Hutan alam secara visual memiliki karakteristik : rona agak gelap dan warna hijau tua dengan tekstur kasar dan pola mengelompok, serta bentuk tajuk 
membulat. Orthophoto hutan tanaman secara visual memiliki karakteristik : rona agak terang dan warna hijau muda dengan tekstur halus dan pola mengelompok, serta bentuk tajuk membulat. Orthophoto lahan terbangun secara visual memiliki karakteristik : rona cerah dan warna merah hingga merah hati, dengan tekstur halus dan pola teratur serta bentuk bangunan tampak dari atas seperti huruf "L" (gedung FKIP), persegi empat (gedung Fahutan), dan persegi panjang (gedung Faperta). Orthophoto lahan terbuka secara visual memiliki karakteristik : rona cerah dan warna abuabu hingga coklat muda dengan tekstur halus dan pola teratur serta bentuk persegi empat dan persegipanjang. Orthophoto badan air secara visual memiliki karakteristik : rona terang dan warna abuabu dengan tekstur halus dan bentuk lahan seperti bangun datar. Orthophoto semak belukar secara visual memiliki karakteristik : rona agak cerah dan warna hijau hingga hijau muda dengan tekstur agak kasar dan pola mengelompok serta bentuk tajuk vegetasi yang membulat. Orthophoto tanaman sawit secara visual memiliki karakteristik : Rona gelap dan warna hijau tua dengan tekstur kasar dan pola teratur.

\section{B. Saran}

Kami menyarankan agar penelitian ini dilanjutkan dengan menganalisa nilai piksel pada foto udara UAV untuk mengetahui karakteristik objek atau tutupan lahan berdasarkan nilai spektral pada band Red, Green dan Blue.

\section{UCAPAN TERIMA KASIH}

Ucapan terimakasih penulis sampaikan kepada Fakultas Kehutanan Universitas Lancang Kuning atas dukungan dana yang diberikan melalui program APBF tahun akademik 2018/2019.

\section{DAFTAR PUSTAKA}

Jaya, INS. (2015). Analisis Citra Digital Persepektif Penginderaan jauh untuk Pengelolaan Sumberdaya Alam. Bogor (ID): Fakultas Kehutanan Institut Pertanian Bogor.

Lillesand, T.M., \& R.W. Kiefer.(1997). Penginderaan Jauh dan Interpretasi Citra. Gadjah Mada University press. Yogyakarta

Radiansyah, Sumantri. (2017). Aplikasi Pesawat Tanpa Awak (UAV)/Drone Untuk Pemantauan Satwa Liar. Tesis. Program Pascasarjana. Institut Pertanian Bogor.

Rosaji, F., Nurvensia, Y. T., Haidir, A., Handayani, W. (2015). Perencanaan, Akuisisi dan Pengolahan Foto Udara 
Menggunakan Teknologi UAV Sebagai Alternatif Pemenuhan Data Spasial. CV. Mitra Geotama, Yogyakarta.

Sutanto. 1986. Penginderaan Jauh Jilid I. Yogyakarta : Gadjah Mada University Press

Shofiyanti, R. (2011). Teknologi Pesawat Tanpa Awak Untuk Pemetaan dan Pemantauan Tanaman dan Lahan Pertanian. Informatika Pertanian, 20(2), 58-64. 